\title{
A Simple Risk Score for Identifying Individuals with Impaired Fasting Glucose in the Southern Chinese Population
}

\author{
Hui Wang 1,2, Tao Liu ${ }^{1}$, Quan Qiu ${ }^{1}$, Peng Ding ${ }^{1}$, Yan-Hui He ${ }^{1}$ and Wei-Qing Chen ${ }^{1, *}$ \\ 1 Guangdong Provincial Key Laboratory of Food, Nutrition and Health, Department of Biostatistics \\ and Epidemiology, School of Public Health, Sun Yat-Sen University, Guangzhou 510080, China; \\ E-Mails: wanghui-78@163.com (H.W.);gztt_2002@163.com (T.L.); qiuquan2008s@126.com (Q.Q.); \\ ben_1234567@hotmail.com (P.D.); hyhhappy2003@163.com (Y.-H.H.) \\ 2 Department of Epidemiology and Biostatistics and Guangdong Key Lab of Molecular Epidemiology, \\ School of Public Health, Guangdong Pharmaceutical University, Guangzhou 510006, China \\ * Author to whom correspondence should be addressed; E-Mail: chenwq@mail.sysu.edu.cn; \\ Tel.: +86-20-8733-2199; Fax: +86-20-8733-0446.
}

Academic Editor: Paul B. Tchounwou

Received: 17 November 2014 / Accepted: 20 January 2015 / Published: 23 January 2015

\begin{abstract}
This study aimed to develop and validate a simple risk score for detecting individuals with impaired fasting glucose (IFG) among the Southern Chinese population. A sample of participants aged $\geq 20$ years and without known diabetes from the 2006-2007 Guangzhou diabetes cross-sectional survey was used to develop separate risk scores for men and women. The participants completed a self-administered structured questionnaire and underwent simple clinical measurements. The risk scores were developed by multiple logistic regression analysis. External validation was performed based on three other studies: the 2007 Zhuhai rural population-based study, the 2008-2010 Guangzhou diabetes cross-sectional study and the 2007 Tibet population-based study. Performance of the scores was measured with the Hosmer-Lemeshow goodness-of-fit test and ROC $c$-statistic. Age, waist circumference, body mass index and family history of diabetes were included in the risk score for both men and women, with the additional factor of hypertension for men. The ROC c-statistic was 0.70 for both men and women in the derivation samples. Risk scores of $\geq 28$ for men and $\geq 18$ for women showed respective sensitivity, specificity, positive predictive value and negative predictive value of $56.6 \%, 71.7 \%, 13.0 \%$ and $96.0 \%$ for men and $68.7 \%, 60.2 \%, 11 \%$ and $96.0 \%$ for women in the derivation population. The scores
\end{abstract}


performed comparably with the Zhuhai rural sample and the 2008-2010 Guangzhou urban samples but poorly in the Tibet sample. The performance of pre-existing USA, Shanghai, and Chengdu risk scores was poorer in our population than in their original study populations. The results suggest that the developed simple IFG risk scores can be generalized in Guangzhou city and nearby rural regions and may help primary health care workers to identify individuals with IFG in their practice.

Keywords: risk assessment; score; impaired fast glucose; Southern Chinese

\section{Introduction}

Pre-diabetes, in which blood glucose concentrations are higher than normal but have not yet met the absolute definition of diabetes, is usually called borderline diabetes and represents a high-risk state for the development of diabetes [1]. Pre-diabetes includes impaired fasting glucose (IFG) and impaired glucose tolerance (IGT). The prevalence of pre-diabetes has rapidly increased in developing countries over the past years [2] and is much higher even than that of type 2 diabetes (T2DM) [3]. Pre-diabetes has high probability to progress to T2DM [3] and is also associated with an increased risk of mortality and macrovascular and microvascular diseases [4]. Many studies have shown that fortunately, lifestyle or medication interventions at the pre-diabetes stage can delay or prevent the progression of pre-diabetes to T2DM [5-10]. However, pre-diabetes is asymptomatic, and the majority of individuals with this condition remain undiagnosed and untreated [2]. Therefore, an important step in delaying or preventing T2DM and its associated complications is to identify individuals with pre-diabetes in the population as early as possible so that they can be treated appropriately.

In past decades, fasting plasma glucose (FPG) and the oral glucose tolerance test (OGTT) were used to screen those with pre-diabetes and undiagnosed T2DM in the population. However, these two methods are unlikely to remain a feasible strategy for tackling the rapidly rising prevalence of pre-diabetes due to their complexity, high cost and invasiveness. Currently, many self-administered risk scores are available to assess undiagnosed diabetes in different countries and regions and for different races [11-23]. The self-administered risk score has many advantages compared with FPG and the OGTT; for example, it is simple, cheap, noninvasive and easily accepted. Presently, to the best of our knowledge, few studies have addressed the establishment of risk scores especially to detect pre-diabetes. Hence, it is necessary to establish such a score that will contribute to diabetic screening and prevention in the Southern Chinese population. The current study aimed to develop a risk score to identify individuals with IFG (a form of pre-diabetes) in the Southern Chinese population and validate the risk score in three other population-based samples. We further compared the performance of our risk score with that of several published risk scores for detecting individuals with IFG in our study population. 


\section{Methods}

\subsection{Population for Establishing the Risk Scores}

The derivation sample of the present study came from the 2006-2007 Guangzhou diabetes cross-sectional population-based survey in urban communities. As described previously [24], multiple-stage random cluster sampling was performed to recruit the study subjects. All residents aged $\geq 20$ years who had lived in Guangzhou for at least 5 years were invited, of whom 6197 took part. We discovered 620 subjects with diagnosed or undiagnosed diabetes before we performed the survey, who were excluded from the study sample.

\subsection{Population for Validating the Risk Scores}

Internal validation of the scores was performed in the derivation sample, and three validation samples were used for external validation. Validation sample 1 was based on the 2007 Zhuhai population-based survey. This survey targeted the rural population of Zhuhai, of whom 1186 individuals took part and 87 individuals with diagnosed or undiagnosed diabetes before the survey were excluded. Validation sample 2 came from the 2008-2010 Guangzhou cross-sectional study on diabetes in urban communities, from which 3162 subjects were recruited and 174 with diabetes were excluded. The study set for validation sample 3 was the 2007 Tibet population-based study with 1289 Tibetan individuals participating [25], of whom 30 with diabetes were excluded. The study design and data collection of the three studies were almost the same as those of the study for the derivation sample. We also used three other risk assessment scores [26-28] and validated them in our derivation population. All of the studies were approved by the ethics committee of Sun Yat-Sen University, and informed consent was obtained from each participant before starting the data collection.

\subsection{Data Collection}

Data on demographic characteristics and health-related behaviors were collected through a self-administered structured questionnaire, and a standardized physical examination (blood pressure, height, weight and waist circumference) was performed on each participant. A venous blood sample was collected in the morning after an overnight fast to measure FPG. All of the above data were collected at local community health care centers.

The related factors are defined as follows: age, body mass index (BMI) and waist circumference were included as continuous variables in the univariate analysis or in the initial models for determination of score performance, and then as fractiles in the final models. Age was divided into four groups: 20-39 years, 40-49 years, 50-59 years and $\geq 60$ years. According to the study of China Obesity Task Force [29], BMI was divided into three groups: $<24 \mathrm{~kg} / \mathrm{m}^{2}, 24 \mathrm{~kg} / \mathrm{m}^{2}$ to $28 \mathrm{~kg} / \mathrm{m}^{2}$ and $\geq 28 \mathrm{~kg} / \mathrm{m}^{2}$. On the basis of the central obesity definitions of the International Diabetes Foundation for Asians [30], waist circumference was divided into two groups: $<90 \mathrm{~cm}$ and $\geq 90 \mathrm{~cm}$ for men and $<80 \mathrm{~cm}$ and $\geq 80 \mathrm{~cm}$ for women. Hypertension was defined as a systolic blood pressure $\geq 140 \mathrm{mmHg}$, diastolic blood pressure $\geq 90 \mathrm{mmHg}$ or diagnosed hypertension and taking antihypertensive drugs for more than 2 weeks [31]. Family history of diabetes was defined as a history of diabetes in first-degree relatives (parents, siblings and children) at any age. 


\subsection{Diagnostic Criteria for Impaired Fasting Glucose (IFG)}

According to the 1999 WHO diagnostic criteria [32], IFG is defined as a fasting plasma glucose concentration from $\geq 6.1 \mathrm{mmol} / \mathrm{L}$ to $<7.0 \mathrm{mmol} / \mathrm{L}$.

\subsection{Statistical Analysis}

The risk scores were derived from the data drawn from the 2006-2007 Guangzhou survey. Candidate prediction variables were selected by univariate logistic regression analysis. Proposed variables were retained if they achieved the set criterion of $p \leq 0.05$ for statistical significance. Considering the varying contributions of risk factors for IFG across sex, we developed the scores for men and women separately using multivariate logistic regression. We added the retained candidate variables (not including the laboratory-tested ones) into the equations one by one from highest to lowest odds ratios according to their values in the univariate analysis. To keep the risk scores simple and easy to use, interaction terms between the independent variables were not considered. The Hosmer-Lemeshow goodness of fit test was performed to determine whether the addition of a variable to a model improved the calibration of the model (the extent of matching between predicted and observed risk of IFG), and the receiver operating characteristic (ROC) $c$-statistic (equivalent to the area under the curve (AUC)) was used to assess whether the addition of a variable to a model improved the discrimination of the model (the ability to stratify high risk or non-high risk for IFG). The point values of the IFG risk scores were derived by multiplying $\beta$, which was derived from the final multivariate regression model, by the constant 10 and were rounded to the nearest integer for ease of use. The higher the score, the greater is the risk of developing IFG.

Cut-off points were used to assess whether individuals are at risk of IFG. with the point beyond the cut-off indicating a high risk of developing IFG. As a non-invasive risk score, our risk score, would be used in the first step of a screening program, so sensitivity should weigh higher than specificity. Consequently, the optimal cut-off points of the risk scores for clinical decision-making in general practice were determined as a minimum level of sensitivity $(75 \%)$ instead of using the largest Youden Index. We also evaluated positive predictive value (PPV) and negative predictive value (NPV) based on the different diabetic prevalence of the different samples. The comparison of ROC-AUCs was performed by Z-test. SPSS 13.0 was used for all statistical analyses.

\section{Results}

\subsection{Characteristics of the Study Populations}

There were 6197 eligible participants in the derivation sample, and the response rate was 95\%. Of these participants, 2094 (33.79\%) were men and 4103 (66.21\%) were women. The prevalence of IFG among the men $(6.9 \%)$ was slightly higher than that among the women $(6.6 \%)$. Among the patients with IFG, the men had a higher prevalence rate of hypertension $(55.6 \% v s .46 .8 \%)$ and a lower prevalence of central obesity $(28.6 \%$ vs. $55.6 \%)$ versus those of the women.

Among all the samples, compared with the participants in the Guangzhou and Zhuhai studies, those in the Tibet study had had a lower prevalence rate of diabetes, IFG and family history of diabetes but had a higher prevalence rate of obesity. The characteristics of the participants are shown in Table 1. 
Table 1. Baseline characteristics of the four different study samples.

\begin{tabular}{cccccc}
\hline Variable or Statistic & $\begin{array}{c}\text { Derivation } \\
\text { Sample }\end{array}$ & $\begin{array}{c}\text { Validation } \\
\text { Sample 1 }\end{array}$ & $\begin{array}{c}\text { Validation } \\
\text { Sample 2 }\end{array}$ & $\begin{array}{c}\text { Validation } \\
\text { Sample 3 }\end{array}$ & $\boldsymbol{P}^{\text {a }}$ Value \\
\hline N (\% of men) & $6033(32.0)$ & $1186(37.8)$ & $3162(28.4)$ & $1289(28.4)$ & -- \\
Mean age (year) & $51.6 \pm 12.7$ & $49.4 \pm 13.2$ & $57.5 \pm 5.2$ & $43.6 \pm 14.3$ & $<0.001$ \\
BMI (kg/m ( $^{2}$ & $23.5 \pm 3.4$ & $23.0 \pm 3.3$ & $23.3 \pm 3.2$ & $24.2 \pm 4.0$ & 0.04 \\
Waist circumference (cm) & $79.1 \pm 9.4$ & $77.7 \pm 9.3$ & $82.4 \pm 9.1$ & $82.4 \pm 12.1$ & $<0.001$ \\
Systolic blood pressure (mmHg) & $123.4 \pm 19.7$ & $128.6 \pm 20.8$ & $123.6 \pm 17.7$ & $120.5 \pm 22.9$ & 0.002 \\
Diastolic blood pressure (mmHg) & $79.1 \pm 10.6$ & $81.6 \pm 10.3$ & $78.2 \pm 10.7$ & $82.4 \pm 14.0$ & 0.01 \\
Fast blood glucose (mmol/L) & $5.54 \pm 1.49$ & $5.63 \pm 1.52$ & $4.77 \pm 1.46$ & $4.92 \pm 1.35$ & 0.03 \\
Number of patients with IFG & 384 & 106 & 95 & 37 & -- \\
IFG (\%) & 6.2 & 8.9 & 3.0 & 2.9 & 0.02 \\
Obesity (\%) ${ }^{\mathbf{b}}$ & 9.0 & 6.9 & 7.1 & 16.9 & 0.01 \\
Central obesity (\%) ${ }^{\mathbf{c}}$ & 32.4 & 34.6 & 41.6 & 45.5 & 0.02 \\
Hypertension (\%) & 32.8 & 33.7 & 34.3 & 30.3 & 0.33 \\
Family history of diabetes (\%) & 17.6 & 6.1 & 16.3 & 2.2 & $<0.001$ \\
\hline
\end{tabular}

Data are means \pm SD or percentages. BMI: body mass index; HDL-C: high-density lipoprotein cholesterol; LDL-C: low-density lipoprotein cholesterol. Derivation sample: the Guangzhou urban sample in the year 2006-2007, including subjects above 20 years old; Validation sample 1: the Zhuhai rural sample, including subjects above 20 years old; Validation sample 2: the Guangzhou sample in the year 2008-2010, including subjects above 40 years old; Validation sample 3: the Tibet sample, including subjects above 20 years old. ${ }^{\mathbf{a}}$ tested by Chi-square or one-way ANOVA. ${ }^{\mathbf{b}}$ Defined as BMI $\geq 28 .{ }^{\mathbf{c}}$ Defined as a waist circumference measurement $\geq 90 \mathrm{~cm}$ for men or $\geq 80 \mathrm{~cm}$ for women.

\subsection{Development of the Risk Scores}

After univariate logistic regression analysis, the candidate prediction variables for the risk scores were age, BMI, waist circumference, systolic blood pressure, diastolic blood pressure and family history of diabetes. The model prediction for both men and women improved significantly $(p<0.05)$ with the addition of the age, BMI, waist circumference and family history of diabetes variables into the equations. Adding the variable of hypertension improved the model prediction significantly for men but not for women. When we added the above variables, which contributed to the equations (scores) one by one, the ROC c-statistic improved slightly each time (results not shown). The formulas for the prediction models for men and for women are as follows, with age, waist circumference and BMI regarded as continuous variables:

$$
\begin{array}{r}
\ln [p /(1-p)] \text { for men }=-8.887+0.04 \times \text { Age }+0.02 \times \text { Waist circumference }+0.09 \times \text { BMI }+ \\
0.25 \times \text { Family history of diabetes }+0.15 \times \text { Hypertension }
\end{array}
$$

and:

$$
\begin{aligned}
\ln [p /(1-p)] \text { for women } & =-8.918+0.04 \times \text { Age }+0.05 \times \text { Waist circumference }+0.008 \times \text { BMI }+ \\
& 0.45 \times \text { Family history of diabetes }
\end{aligned}
$$

The final models and the point values of the risk scores are shown in Table 2. The scores were the point values ranging between 0 to the maximum scores in Table 2. 
Table 2. $\beta$-coefficient, ORs and risk scores of predictors in the models for detecting IFG based on the derivation sample.

\begin{tabular}{|c|c|c|c|c|c|c|}
\hline \multirow{2}{*}{ Variable or Statistic } & \multicolumn{3}{|c|}{ Men } & \multicolumn{3}{|c|}{ Women } \\
\hline & $\beta$ Coefficient & OR $(95 \%$ CI $)$ & Score & $\beta$ Coefficient & OR $(95 \%$ CI $)$ & Score \\
\hline Age(years): 20-39 & -- & 1.00 & 0 & -- & 1.00 & 0 \\
\hline $40-49$ & 1.77 & $5.85(1.68-20.34)$ & 18 & 1.10 & $3.00(1.53-5.90)$ & 11 \\
\hline $50-59$ & 1.95 & $6.99(2.12-23.03)$ & 19 & 1.53 & $4.59(2.42-8.72)$ & 15 \\
\hline Over 60 & 2.04 & $7.69(2.33-25.40)$ & 20 & 1.95 & $7.03(3.68-13.41)$ & 20 \\
\hline Waist circumference $(\mathrm{cm})$ : men $<90$, women $<80$ & -- & 1.00 & 0 & -- & 1.00 & 0 \\
\hline men $\geq 90$,women $\geq 80$ & -0.12 & $0.89(0.55-1.43)$ & -1 & 0.54 & $1.72(1.20-2.48)$ & 5 \\
\hline \multicolumn{7}{|l|}{ Family history of diabetes: } \\
\hline No & -- & 1.00 & 0 & -- & 1.00 & 0 \\
\hline Yes & 0.16 & $1.18(0.69-2.01)$ & 2 & 0.46 & $1.58(1.12-2.22)$ & 5 \\
\hline BMI: BMI < 24 & -- & 1.00 & 0 & -- & 1.00 & 0 \\
\hline $24 \leq \mathrm{BMI}<28$ & 0.44 & $1.56(0.93-2.61)$ & 4 & 0.09 & $1.09(0.76-1.58)$ & 1 \\
\hline $\mathrm{BMI} \geq 28$ & 0.93 & $2.54(1.33-4.86)$ & 9 & 0.49 & $1.63(1.00-2.64)$ & 5 \\
\hline Hypertension: No & -- & 1.00 & 0 & -- & -- & -- \\
\hline Yes & 0.78 & $2.19(1.43-3.35)$ & 8 & -- & -- & -- \\
\hline Maximum score & & & 38 & & & 35 \\
\hline
\end{tabular}

BMI: body mass index. 


\subsection{Internal and External Validation of the Risk Scores}

For the internal validation of the risk scores for both men and women, the $p$ values of the Hosmer-Lemeshow goodness-of-fit tests were 0.40 and 0.38 , respectively, and the values of the ROC c-statistic were 0.70 for both sexes (Table 3 and Figure 1). We also calculated the ROCs of single anthropometrics variables for predicting IFG. The values of the ROCs of the single BMI and waist circumference variables were 0.64 and 0.67 , respectively, for women, and 0.61 for both for men, and all were lower than those of the risk scores.

Table 3. Internal and external validation studies of the different models.

\begin{tabular}{rcc}
\hline Validation & Model for Men & Model for Women \\
\hline Internal validation studies in the derivation sample & \\
Goodness of fit $(P$ value $)$ & 0.40 & 0.38 \\
ROC $c$-statistic $(95 \%$ CI $)$ & $0.70(0.65-0.74)$ & $0.70(0.67-0.73)$ \\
External validation studies in the validation sample 1 & \\
Goodness of fit $(P$ value $)$ & 0.59 & 0.96 \\
ROC $c$-statistic $(95 \%$ CI $)$ & $0.75(0.67-0.83)$ & $0.77(0.71-0.83)$ \\
External validation studies in the validation sample 2 & \\
Goodness of fit $(P$ value $)$ & 0.78 & 0.56 \\
ROC $c$-statistic $(95 \%$ CI $)$ & $0.74(0.61-0.86)$ & $0.72(0.65-0.78)$ \\
External validation studies in the validation sample 3 & \\
Goodness of fit $(P$ value $)$ & 0.49 & 0.54 \\
ROC $c$-statistic $(95 \%$ CI $)$ & $0.31(0.20-0.43)$ & $0.50(0.38-0.61)$ \\
\hline
\end{tabular}

BMI: body mass index; WC: waist circumference. Derivation sample: the 2006-2007 Guangzhou urban sample; Validation sample 1: the Zhuhai rural sample; Validation sample 2: the 2008-2010 Guangzhou urban sample; Validation sample 3: the Tibet sample. Goodness of fit was tested by Hosmer-Lemeshow test.

A.

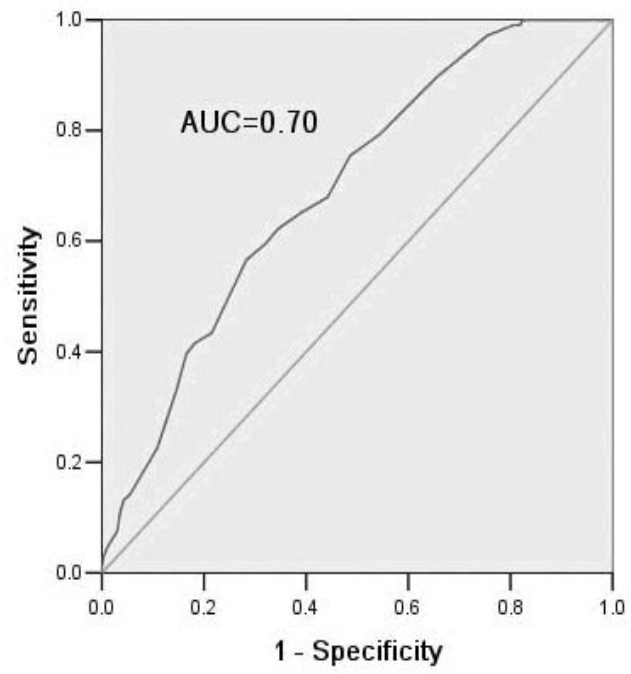

B.

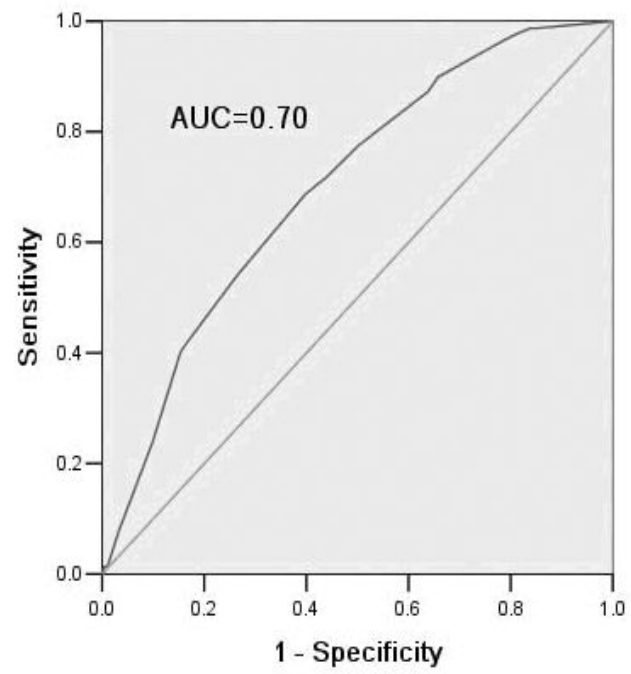

Figure 1. Cont. 
C.

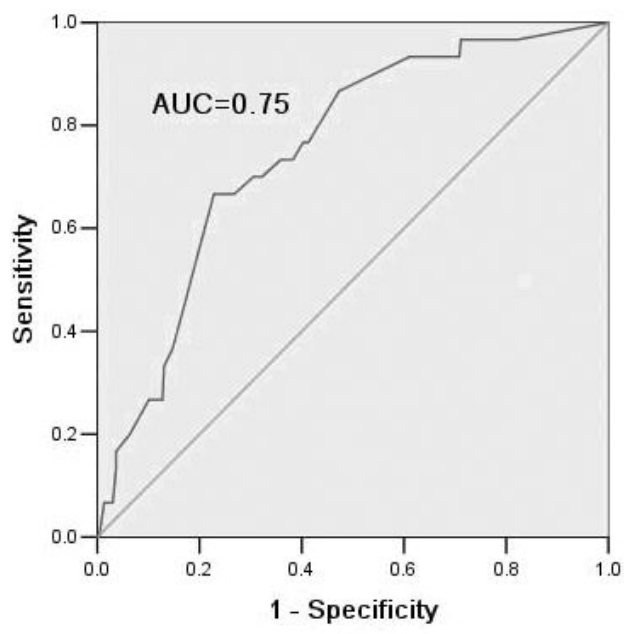

E.

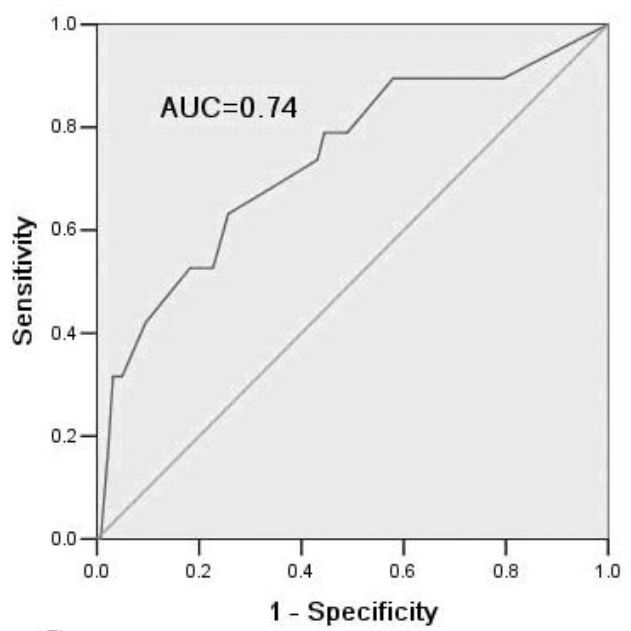

G.

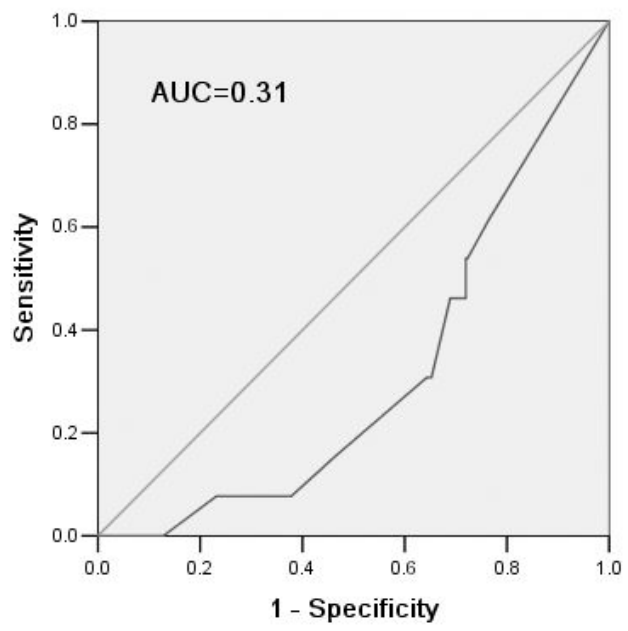

D.

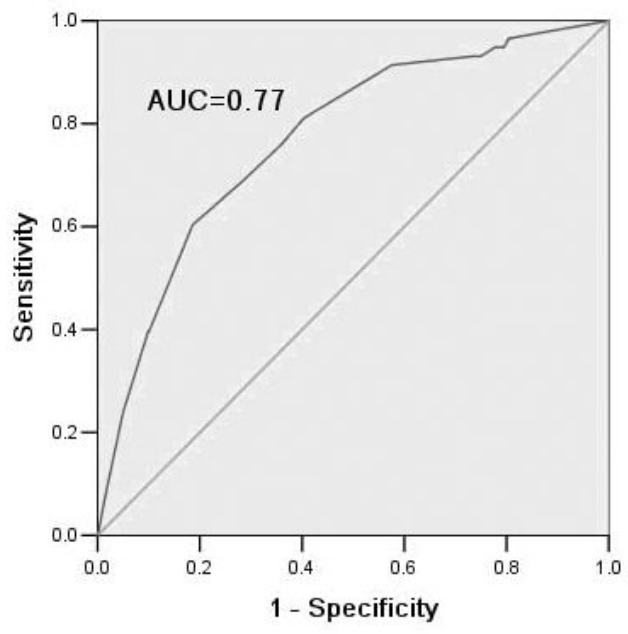

F.



H.

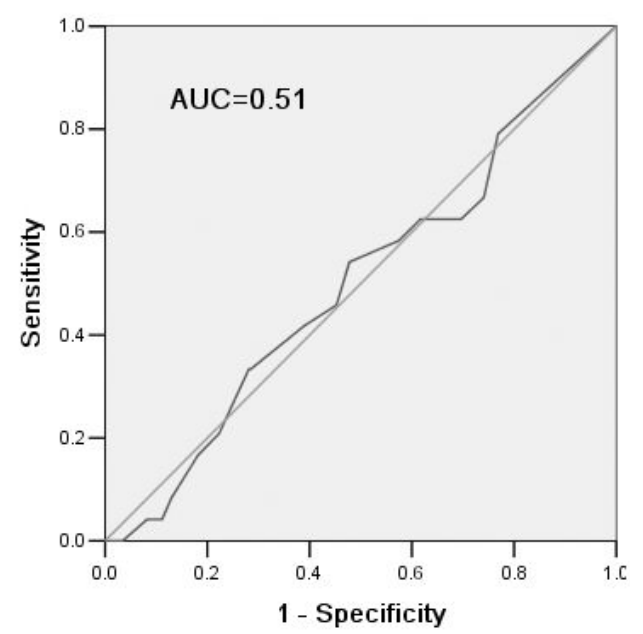

Figure 1. ROC curves of the risk scores for detecting IFG. (A). ROC curve for men in the derivation sample; (B). ROC curve for women in the derivation sample; (C). ROC curve for men in the validation sample 1; (D). ROC curve for women in the validation sample 1; (E). ROC curve for men in the validation sample 2; (F). ROC curve for women in the validation sample 2; (G). ROC curve for men in the validation sample 3; (H). ROC curve for women in the validation sample 3. 
The optimal cut-off points of the risk scores were 23 for men and 16 for women. These cut-off points defined approximately $50.5 \%$ and $52.1 \%$ of the derivation population as having IFG for the men and women, respectively. Sensitivity, specificity, PPV and NPV were 75.5\%, 51.4\%, 12.0\% and 97.0\% for men and $77.5 \%, 49.8 \%, 10 \%$ and $97.0 \%$ for women, respectively, in the derivation population (Table 4 ). In the external validation, the risk scores performed well in the Zhuhai rural sample and the 2008-2010 Guangzhou urban sample: The $p$ values of the Hosmer-Lemeshow goodness-of-fit tests were between 0.56 and 0.96 , and the values of the ROC c-statistic were from 0.72 to 0.77 (Table 3 and Figure 1). However, the values of the ROC c-statistic of the risk scores in the Tibet sample were 0.31 for men and 0.51 for women, respectively. Sensitivity, specificity, PPV and NPV at the optimal cut-off points of risk scores (23 for men and 16 for women) in the three validation samples are presented in Table 4 . Compared with the performance in the derivation sample, the three validation samples had similar specificity and NPV. Validation sample 1 (Zhuhai rural sample) had a much higher PPV than the other validation samples. Although the PPV of validation sample 2 (2008-2010 Guangzhou sample) was lower than that of the derivation sample, the NPV was higher. However, both the sensitivity and specificity of validation sample 3 (the Tibet sample) were less than those of the other samples.

Table 4. The performance of the risk score at cut-off points for detecting IFG in the derivation sample and validation samples.

\begin{tabular}{|c|c|c|c|c|c|}
\hline Total Score & Number $(\%)$ & Sensitivity(\%) & Specificity (\%) & PPV (\%) & NPV (\%) \\
\hline \multicolumn{6}{|c|}{ Derivation sample } \\
\hline \multicolumn{6}{|l|}{ Model for men } \\
\hline$\geq 23$ & $747(50.5)$ & 75.5 & 51.4 & 12 & 97 \\
\hline \multicolumn{6}{|l|}{ Model for women } \\
\hline$\geq 16$ & $1755(52.1)$ & 77.5 & 49.8 & 10 & 97 \\
\hline \multicolumn{6}{|c|}{ Validation sample 1} \\
\hline $\operatorname{Men}(\geq 23)$ & $136(41.5)$ & 73.3 & 64.1 & 13 & 97 \\
\hline Women $(\geq 16)$ & $255(44.4)$ & 81.0 & 59.7 & 19 & 96 \\
\hline \multicolumn{6}{|c|}{ Validation sample 2} \\
\hline $\operatorname{Men}(\geq 23)$ & $430(51.7)$ & 78.9 & 51.0 & 6 & 99 \\
\hline Women $(\geq 16)$ & $1254(58.1)$ & 89.3 & 41.8 & 5 & 99 \\
\hline \multicolumn{6}{|c|}{ Validation sample 3} \\
\hline $\operatorname{Men}(\geq 23)$ & $160(41.1)$ & 30.8 & 48.8 & 2 & 96 \\
\hline Women $(\geq 16)$ & $362(40.5)$ & 41.7 & 59.0 & 4 & 96 \\
\hline
\end{tabular}

PPV: positive predictive value; NPV: negative predictive value; Derivation sample: The 2006-2007 Guangzhou urban sample. Validation sample 1: the Zhuhai rural sample; Validation sample 2: the 2008-2010 Guangzhou urban sample; Validation sample 3: the Tibet sample.

\subsection{Comparison of the Current Risk Scores with Other Existing Scores for Pre-Diabetes}

The AUCs of the risk scores in the USA [26], Chengdu [27] and Shanghai [28] original populations were similar to those our scores, but performance of the scores was poorer in our population than in the original study populations, which can be seen by comparison with their AUCs ( 0.66 vs. 0.74 for the USA score; $0.67 v s .0 .70$ for the Shanghai score; and 0.66 vs. 0.72 for men and $0.67 v s .0 .73$ for women for the Chengdu score) (Table 5). 
Table 5. Other pre-diabetes risk scores developed in other populations and performances in the current derivation study population.

\begin{tabular}{|c|c|c|c|c|c|c|c|c|c|}
\hline \multirow{2}{*}{$\begin{array}{c}\text { Derivation } \\
\text { Population } \\
\text { (Publication } \\
\text { Year) }\end{array}$} & \multirow[b]{2}{*}{ Predictors Involved } & \multirow{2}{*}{$\begin{array}{c}\text { Optimal } \\
\text { Cut-Off } \\
\text { Value } \\
\text { (Range) }\end{array}$} & \multicolumn{3}{|c|}{ Area under the $(95 \% \mathrm{CI})$} & \multicolumn{2}{|c|}{$\begin{array}{c}\text { Sensitivity at the Optimal } \\
\text { Cut-Off Value (\%) } \\
\end{array}$} & \multicolumn{2}{|c|}{$\begin{array}{c}\text { Specificity at the Optimal Cut-off } \\
\text { Value (\%) }\end{array}$} \\
\hline & & & $\begin{array}{l}\text { In Original } \\
\text { Population }\end{array}$ & $\begin{array}{l}\text { In the Population of } \\
\text { This Study }\end{array}$ & $p$ Value * & $\begin{array}{l}\text { In Original } \\
\text { Population }\end{array}$ & $\begin{array}{c}\text { In the } \\
\text { Population of } \\
\text { This Study } \\
\end{array}$ & $\begin{array}{l}\text { In Original } \\
\text { Population }\end{array}$ & $\begin{array}{c}\text { In the Population } \\
\text { of This Study }\end{array}$ \\
\hline USA (2008) & $\begin{array}{l}\text { Age, sex, BMI, hypertension, family history of } \\
\text { diabetes, resting heart rate }\end{array}$ & $5(0-16)$ & 0.74 & $0.66(0.63-0.68)$ & 0.04 & 87.0 & 92.0 & 43.3 & 26.4 \\
\hline $\begin{array}{c}\text { Shanghai, } \\
\text { China (2009) }\end{array}$ & $\begin{array}{c}\text { Age, waist circumference, family history of } \\
\text { diabetes, systolic blood pressure }\end{array}$ & $5(4-11.7)$ & 0.70 & $0.67(0.64-0.70)$ & 0.06 & 68.2 & 68.5 & 61.7 & 54.9 \\
\hline \multirow{2}{*}{$\begin{array}{c}\text { Chengdu, } \\
\text { China (2010) }\end{array}$} & $\begin{array}{l}\text { Age, occupational physical activity, family } \\
\text { history of diabetes, BMI, central obesity, }\end{array}$ & $\begin{array}{c}\text { Men: } \\
5(0-18)\end{array}$ & $\begin{array}{c}\text { Men: } \\
0.72(0.69-0.74)\end{array}$ & $\begin{array}{c}\text { Men: } \\
0.66(0.61-0.72)\end{array}$ & \multirow{2}{*}{0.06} & Men: 74.1 & Men: 73.3 & Men: 58.4 & Men: 54.2 \\
\hline & $\begin{array}{l}\text { hypertension, leisure physical activity, } \\
\text { gestational diabetes, number of deliveries }\end{array}$ & $\begin{array}{l}\text { Women: } \\
6(0-22)\end{array}$ & $\begin{array}{c}\text { Women: } \\
0.73(0.71-0.75)\end{array}$ & $\begin{array}{c}\text { Women: } \\
0.67(0.63-0.71)\end{array}$ & & Women: 75.6 & Women: 44.5 & Women: 65.6 & Women: 76.1 \\
\hline
\end{tabular}

* compared with the AUC of the IFG risk scores in our study. 


\section{Discussion}

Using data from a community-based cross-sectional survey on T2DM in adult populations from Guangzhou, China [24], we developed a simple risk score for detecting IFG among men or women in this particular population. Factors included in the risk score for both sexes were age, family history of diabetes, waist circumference and BMI for women, with the additional variable of hypertension for men. Internal validation proved that the scores were sensitive and specific for detecting IFG, and further external validation showed that the scores had good overall performance, good calibration and good discrimination in the investigated Southern Chinese population.

To date, a number of risk scores for detecting individuals with undiagnosed T2DM (or pre-diabetes included) have been developed for different countries and different races [13-15,18,20-23,33-35]. Most were established for individuals aged over 35 years old [13,15,21-23,33-35]. For example, a quick self-assessment tool was developed in a Chinese population aged 35-74 years to identify individuals at high risk of type 2 diabetes [23], and a risk score for predicting incident diabetes in a Thai population was developed for subjects aged 35-55 years [15]. However, given the increasing burden of T2DM among youthful populations, we expect IFG to occur at even younger ages. As we expected, the prediction models for undiagnosed diabetes in our previous study are weighted more toward age and waist circumference, and less toward BMI, than the prediction models for pre-diabetes in this study, so the existing models for predicting the risk of developing diabetes may not be especially suitable for individuals with IFG. Accordingly, the establishment of specific risk scores to identify individuals at high risk of pre-diabetes is necessary.

Similar to the risk scores for undiagnosed diabetes that we developed previously, we designed the models in this study to use only those factors that can be either self-reported or easily measured. Further, we developed separate risk scores for detecting IFG in men and women. All of the risk factors in our scores are easily obtained by asking several questions or by anthropometric measurements, thus allowing a simple, inexpensive, quick and noninvasive process. Therefore, our risk scores may provide primary health care workers with a tool to assess their patient's risk of IFG using the patients' health records. The scores also have potential application as web-based screening tools to improve health awareness and to encourage compliance with physician-recommended lifestyle changes.

Internal and external validation proved the good overall performance of our scores in the Southern Chinese population investigated. The AUCs of our risk scores for both men and women (0.70) were similar to the AUCs of risk scores developed in the USA (0.74) [26] and in Chengdu, a provincial capital city in Western China ( 0.72 for men and 0.73 for women) [27], indicating that our risk scores appeared to perform comparably with existing risk scores using quantitative criteria, although small differences were present.

On the basis of our scores, a man with a score of $\geq 23$ or a woman with a score of $\geq 16$ would be regarded as being at risk of IFG and would be advised to undergo additional testing. The sensitivity and specificity at these two scores were $75.5 \%$ and $51.4 \%$ in men $77.5 \%$ and $49.8 \%$ in women, respectively, which varied slightly from those of the pre-diabetes risk scores for the USA residents $(87.0 \%$ and 43.3\%) [26], Shanghai urban residents (68.2\% and 61.7\%) [28] and Chengdu residents (74.1\% and $58.4 \%$ for men; $75.6 \%$ and $65.6 \%$ for women) [27]. This may be due to the different performances between these risk scores. 
Performance of our risk scores developed in the southern Chinese population investigated proved to be poor in a population in Tibet (a high-altitude region of Southwest China) through external validation. This result again confirmed that specific risk scores must be developed for different populations in different areas, as shown in previous studies on the development of risk scores to identify individuals with undiagnosed diabetes [36,37]. For instance, a study by Ramachandran et al. [20] proved that a diabetes risk score developed for a native Asian Indian population could not be generalized to South Asian residents in the UK. Another study by Glümer et al. [36] showed that the risk scores for undiagnosed T2DM developed and validated in Caucasians performed similarly in other Caucasian populations but poorly in non-Caucasian populations. Furthermore, we used our derivation population to validate three existing pre-diabetes risk assessment scores and compared the AUCs between them. The AUCs of the scores for the USA [26], Chengdu [27] and Shanghai [28] original populations were similar to those of our scores, but the scores showed poorer performance in our population than in their original populations. One possible explanation may be that genetic and environmental determinants for T2DM or pre-diabetes may differ between different ethnic groups. The people in validation sample 3 are Tibetans who live at an altitude of more than $3600 \mathrm{~m}$ in Southwest China and have a different genetic background, diet, lifestyle and climate from the derivation sample of Cantonese in Guangzhou. Another possible reason is that the distribution of risk factors for populations of the same ethnicity living in a different cultural context, such as different body size, diet, lifestyle and climate, may be different. Our derivation sample, validation sample 1 and validation sample 2 comprise people of Cantonese ethnicity (a branch of Han Chinese) living in the Pearl River Delta region in the southern areas of China who share a similar diet, lifestyle and culture. However, Han Chinese in Shanghai and Chengdu live in eastern or southwestern areas of China, respectively, and compared with the Cantonese, they tend to have a larger body frame and their diet consists of more sweet or spicy foods. Summarily, our risk scores derived from the Guangzhou population are suitable only for people living in the Pearl River Delta region in Southern China and not for all Chinese.

There are several advantages of the present study. First, the risk scores are very simple and relatively easy to interpret, so they can be used by general practitioners in poorer areas and even by the general population. Second, the derivation sample was from a community population-based study, so representation was good. Quality control in this study was good and included strict training of investigators, uniform protocols, face-to-face investigations, standardized tests and severe re-checking rules. Third, we used three independent validation samples comprising varied populations in Southern China, Guangzhou and Tibet. Finally, the sample size was adequate to achieve good statistical power and stability of the developed scores.

The present study also has several limitations. First, it examined only FPG as an outcome. Although there is substantial overlap between impaired fasting glucose and impaired glucose tolerance, we did not address impaired glucose tolerance, which would require an OGTT. When considering probable compliance rates of the OGTT, however, using FPG levels may be the best initial strategy to screen for pre-diabetes [38]. Second, the risk scores for detecting IFG developed in the present study were based on cross-sectional data, and therefore, they can only be used to identify prevalent cases of IFG rather than incident cases of IFG.

Additionally, in primary care settings, practitioners should consider two aspects. First, because the PPV and NPV of the proposed risk score will vary based on the prevalence of IFG in the populations 
tested, practitioners should use this IFG prediction tool according to the actual conditions. Second, the risk scores have high sensitivity and high NPV. Therefore, practitioners should inform their patients with scores above the cut-off values that they have a potential risk of developing diabetes and should change their unhealthy lifestyles to reduce the risk of the onset of diabetes.

\section{Conclusions}

We have developed two simple risk scores that can be used to screen for IFG separately in Southern Chinese men and women and have done so using only routinely collected information with no laboratory tests required. A subject with a score above the cut-off value has a potential risk of developing diabetes and should be advised to change his/her unhealthy lifestyle to reduce the risk of the onset of diabetes. Internal and external validation showed that the scores performed well. Our results suggest that the risk scores could be used to detect IFG in the Southern Chinese population or a population in which the distribution of risk factors and their association with prevalent IFG are similar.

\section{Acknowledgments}

This study was funded by the Guangzhou Health Bureau (2005-Zda-001) and was completed with the assistance of the following units: Disease Prevention and Control Center of Haizhu District and Baiyun District, the Health Monitoring Institute of Huangpu District, the Sixth Affiliated Hospital of Sun Yat-sen University, and the Health Care Center of Huayin Community.

\section{Author Contributions}

Hui Wang contributed to study design, data collection, data analysis, result interpretation, and drafting manuscript. Wei-Qing Chen contributed to study design, data analysis plan, result interpretation, and revising the manuscript. Tao Liu, Quan Qiu, Peng Ding, Yan-Hui He contributed to field survey, blood sample collection, and laboratory tests. All authors read and approved the final manuscript.

\section{Conflicts of Interest}

All the authors declare no conflicts of interest.

\section{References}

1. Davidson, M.B. Metabolic syndrome/insulin resistance syndrome/pre-diabetes: New section in diabetes care. Diabetes Care 2003, 26, doi:10.2337/diacare.26.11.3179.

2. King, H.; Aubert, R.E.; Herman, W.H. Global burden of diabetes, 1995-2025: Prevalence, numerical estimates, and projections. Diabetes Care 1998, 21, 1414-1431.

3. Nichols, G.A.; Hillier, T.A.; Brown, J.B. Progression from newly acquired impaired fasting glusose to type 2 diabetes. Diabetes Care 2007, 30, 228-233.

4. Echouffo-Tcheugui, J.B.; Mayige, M.; Ogbera, A.O.; Sobngwi, E.; Kengne, A.P. Screening for hyperglycemia in the developing world: Rationale, challenges and opportunities. Diabetes Res. Clin. Pract. 2012, 98, 199-208. 
5. Perreault, L.; Kahn, S.E.; Christophi, C.A.; Knowler, W.C.; Hamman, R.F. Regression from pre-diabetes to normal glucose regulation in the diabetes prevention program. Diabetes Care 2009, $32,1583-1588$.

6. Pan, X.R.; Li, G.W.; Hu, Y.H.; Wang, J.X.; Yang, W.Y.; An, Z.X.; Hu, Z.X.; Lin, J.; Xiao, J.Z.; Cao, H.B.; et al. Effects of diet and exercise in preventing NIDDM in people with impaired glucose tolerance. The Da Qing IGT and Diabetes Study. Diabetes Care 1997, 20, 537-544.

7. Tuomilehto, J.; Lindstrom, J.; Eriksson, J.G.; Valle, T.T.; Hamalainen, H.; Ilanne-Parikka, P.; Keinanen-Kiukaanniemi, S.; Laakso, M.; Louheranta, A.; Rastas, M.; et al. Prevention of type 2 diabetes mellitus by changes in lifestyle among subjects with impaired glucose tolerance. $N$. Engl. J. Med. 2001, 344, 1343-1350.

8. Knowler, W.C.; Barrett-Connor, E.; Fowler, S.E.; Hamman, R.F.; Lachin, J.M.; Walker, E.A.; Nathan, D.M. Reduction in the incidence of type 2 diabetes with lifestyle intervention or metformin. N. Engl. J. Med. 2002, 346, 393-403.

9. Ramachandran, A.; Snehalatha, C.; Mary, S.; Mukesh, B.; Bhaskar, A.D.; Vijay, V. The Indian Diabetes Prevention Programme shows that lifestyle modification and metformin prevent type 2 diabetes in Asian Indian subjects with impaired glucose tolerance (IDPP-1). Diabetologia 2006, 49, 289-297.

10. Chiasson, J.L.; Josse, R.G.; Gomis, R.; Hanefeld, M.; Karasik, A.; Laakso, M. Acarbose for prevention of type 2 diabetes mellitus: The STOP-NIDDM randomised trial. Lancet 2002, 359, 2072-2077.

11. Baan, C.A.; Ruige, J.B.; Stolk, R.P.; Witteman, J.C.; Dekker, J.M.; Heine, R.J.; Feskens, E.J. Performance of a predictive model to identify undiagnosed diabetes in a health care setting. Diabetes Care 1999, 22, 213-219.

12. Griffin, S.J.; Little, P.S.; Hales, C.N.; Kinmonth, A.L.; Wareham, N.J. Diabetes risk score: Towards earlier detection of type 2 diabetes in general practice. Diabetes Metab. Res. Rev. 2000, 16, 164-171.

13. Lindstrom, J.; Tuomilehto, J. The diabetes risk score: A practical tool to predict type 2 diabetes risk. Diabetes Care 2003, 26, 725-731.

14. Glumer, C.; Carstensen, B.; Sandbaek, A.; Lauritzen, T.; Jorgensen, T.; Borch-Johnsen, K. A Danish diabetes risk score for targeted screening: The Inter99 study. Diabetes Care 2004, 27, 727-733.

15. Aekplakorn, W.; Bunnag, P.; Woodward, M.; Sritara, P.; Cheepudomwit, S.; Yamwong, S.; Yipintsoi, T.; Rajatanavin, R. A risk score for predicting incident diabetes in the Thai population. Diabetes Care 2006, 29, 1872-1877.

16. Schulze, M.B.; Hoffmann, K.; Boeing, H.; Linseisen, J.; Rohrmann, S.; Mohlig, M.; Pfeiffer, A.F.; Spranger, J.; Thamer, C.; Haring, H.U.; et al. An accurate risk score based on anthropometric, dietary, and lifestyle factors to predict the development of type 2 diabetes. Diabetes Care 2007, $30,510-515$.

17. Chien, K.; Cai, T.; Hsu, H.; Su, T.; Chang, W.; Chen, M.; Lee, Y.; Hu, F.B. A prediction model for type 2 diabetes risk among Chinese people. Diabetologia 2009, 52, 443-450.

18. Ko, G.; So, W.; Tong, P.; Ma, R.; Kong, A.; Ozaki, R.; Chow, C.; Cockram, C.; Chan, J. A simple risk score to identify Southern Chinese at high risk for diabetes. Diabet. Med. 2010, 27, 644-649. 
19. Gao, W.G.; Dong, Y.H.; Pang, Z.C.; Nan, H.R.; Wang, S.J.; Ren, J.; Zhang, L.; Tuomilehto, J.; Qiao, Q. A simple Chinese risk score for undiagnosed diabetes. Diabet. Med. 2010, 27, 274-281.

20. Ramachandran, A.; Snehalatha, C.; Vijay, V.; Wareham, N.J.; Colagiuri, S. Derivation and validation of diabetes risk score for urban Asian Indians. Diabetes Res. Clin. Pract. 2005, 70, 63-70.

21. Franciosi, M.; de Berardis, G.; Rossi, M.C.; Sacco, M.; Belfiglio, M.; Pellegrini, F.; Tognoni, G.; Valentini, M.; Nicolucci, A. Use of the diabetes risk score for opportunistic screening of undiagnosed diabetes and impaired glucose tolerance: The IGLOO (impaired glucose tolerance and long-term outcomes observational) study. Diabetes Care 2005, 28, 1187-1194.

22. Thomas, C.; Hypponen, E.; Power, C. Type 2 diabetes mellitus in midlife estimated from the Cambridge Risk Score and body mass index. Arch. Intern. Med. 2006, 166, 682-688.

23. Bang, H.; Edwards, A.M.; Bomback, A.S.; Ballantyne, C.M.; Brillon, D.; Callahan, M.A.; Teutsch, S.M.; Mushlin, A.I.; Kern, L.M. Development and validation of a patient self-assessment score for diabetes risk. Ann. Intern. Med. 2009, 151, 775-783.

24. Wang, H.; Qiu, Q.; Tan, L.L.; Liu, T.; Deng, X.Q.; Chen, Y.M.; Chen, W.; Yu, X.Q.; Hu, B.J.; Chen, W.Q. Prevalence and determinants of diabetes and impaired fasting glucose among urban community-dwelling adults in Guangzhou, China. Diabetes Metab. 2009, 35, 378-384.

25. Chen, W.; Liu, Q.; Wang, H.; Chen, W.; Johnson, R.J.; Dong, X.; Li, H.; Ba, S.; Tan, J.; Luo, N.; et al. Prevalence and risk factors of chronic kidney disease: A population study in the Tibetan population. Nephrol. Dial. Transplant. 2011, 26, 1592-1599.

26. Koopman, R.J.; Mainous, A.R.; Everett, C.J.; Carter, R.E. Tool to assess likelihood of fasting glucose impairment (TAG-IT). Ann. Fam. Med. 2008, 6, 555-561.

27. Huang, X.B.; Zeng, W.; Ouyang, L.Y.; Liu, Y.; Luan, R.S.; Zhang, T.J.; Xu, J.B.; Zhao, S.Q.; Li, X.J.; Huang, B.; et al. Development of evaluation tool for the risk level of abnormal glucose metabolism morbidity in middle-aged and elder populations. Zhonghua Yi Xue Za Zhi 2010, 90, 839-843. (In Chinese)

28. Yu, J.; Zhou, J.; Li, Y. The Screening Model Construction and its validity evaluation for population with impaired glucose Regulation in community. Chin. J. Prev. Contr. Chron. Dis. 2009, 17, 139-141.

29. Cooperative Meta-analysis Group of China Obesity Task Force. Predictive values of body mass index and waist circumference to risk factors of related diseases in Chinese adult population. Chin. J. Epidemiol. 2002, 23, 5-10.

30. International Diabetes Foundation. IDF Consensus Worldwide Definition of the Metabolic Syndrome. Available online: http://www.idf.org/webdata/docs/IDF_Meta_def_final.pdf (accessed on 21 January 2015).

31. Chalmers, J.; MacMahon, S.; Mancia, G.; Whitworth, J.; Beilin, L.; Hansson, L.; Neal, B.; Rodgers, A.; Ni Mhurchu, C.; Clark, T. 1999 World Organization-international society of hypertension guidelines for the management of hypertension. J. Hypertens. 1999, 17, 151-183.

32. Alberti, K.G.; Zimmet, P.Z. Definition, diagnosis and classification of diabetes mellitus and its complications. Part 1: Diagnosis and classification of diabetes mellitus provisional report of a WHO consultation. Diabet. Med. 1998, 15, 539-553. 
33. Gray, L.J.; Taub, N.A.; Khunti, K.; Gardiner, E.; Hiles, S.; Webb, D.R.; Srinivasan, B.T.; Davies, M.J. The Leicester Risk Assessment score for detecting undiagnosed type 2 diabetes and impaired glucose regulation for use in a multiethnic UK setting. Diabet. Med. 2010, 27, 887-895.

34. Heikes, K.E.; Eddy, D.M.; Arondekar, B.; Schlessinger, L. Diabetes risk calculator: A simple tool for detecting undiagnosed diabetes and pre-diabetes. Diabetes Care 2008, 31, 1040-1045.

35. Xin, Z.; Yuan, J.; Hua, L.; Ma, Y.H.; Zhao, L.; Lu, Y.; Yang, J.K. A simple tool detected diabetes and prediabetes in rural Chinese. J. Clin. Epidemiol. 2010, 63, 1030-1035.

36. Glumer, C.; Vistisen, D.; Borch-Johnsen, K.; Colagiuri, S. Risk scores for type 2 diabetes can be applied in some populations but not all. Diabetes Care 2006, 29, 410-414.

37. Glumer, C.; Borch-Johnsen, K.; Colagiuri, S. Can a screening programme for diabetes be applied to another population? Diabet. Med. 2005, 22, 1234-1238.

38. Zhang, P.; Engelgau, M.M.; Valdez, R.; Benjamin, S.M.; Cadwell, B.; Narayan, K.M. Costs of screening for pre-diabetes among US adults: A comparison of different screening strategies. Diabetes Care 2003, 26, 2536-2542.

(C) 2015 by the authors; licensee MDPI, Basel, Switzerland. This article is an open access article distributed under the terms and conditions of the Creative Commons Attribution license (http://creativecommons.org/licenses/by/4.0/). 